\title{
THE PATHOGENESIS OF AZOTEMIA IN HEMORRHAGE FROM THE UPPER GASTRO-INTESTINAL TRACT ${ }^{1}$
}

\author{
By JOHN B. JOHNSON 2 \\ (From the Department of Medicine, University of Rochester School of Medicine and Dentistry \\ and the Medical Clinic of the Strong Memorial and Rochester \\ Municipal Hospitals, Rochester)
}

(Received for publication October 11, 1940)

In 1934 Sanguinetti (1) observed a rise in the blood urea after hemorrhage into the gastro-intestinal tract. This observation has been confirmed in many subsequent reports. It has been shown that not all patients with comparable degrees of hemorrhage from the upper gastro-intestinal tract develop azotemia. The reason for this disparity has not been clarified. Several theories, none of which has been universally accepted, have been proposed to explain the pathogenesis of posthemorrhagic azotemia: (1) Toxic destruction of body protein $(1,2,3,12) ;(2)$ toxicosis due to bacterial decomposition of the stagnant blood ( 1 , 4) ; (3) absorption of digested blood $(1,5,6,7)$; (4) abnormality of chloride metabolism $(6,8)$; and (5) functional impairment of renal activity $(6,7,9,10,12,13,14)$.

This communication reports a study of 17 patients with upper gastro-intestinal hemorrhage. Our observations support the opinion that azotemia following hemorrhage into the stomach and upper part of the small intestines occurs only when the kidney function is temporarily or permanently reduced. Evidence is presented which indicates that such azotemia is due to an accentuation and prolongation of the normal physiological rise in the blood nonprotein nitrogen which follows the ingestion of a large amount of protein.

\section{GENERAL PROCEDURE AND METHODS}

Blood for chemical analysis, hemoglobin, and erythrocyte counts was taken on admission to the hospital and at frequent intervals as indicated in the tables. Renal function was studied by repeated measurement of the urea and creatinine clearances. In most instances, the initial observations on renal function were begun within a few hours after admission to the hospital. The blood urea nitrogen was measured by the manometric urease

1 Presented in abstract at the meeting of the American Society for Clinical Investigation, May 6, 1940, Atlantic City, New Jersey.

2 Rockefeller Foundation Fellow in Medicine. method of Van Slyke (19). Blood serum chloride (blood collected under oil) was determined by the method of Van Slyke and Sendroy (19). Nonprotein nitrogen was determined by the micro Kjeldahl and direct nesslerization method of Wong (19). Plasma carbon dioxide combining power was measured by the method of Van Slyke and Cullen (19). Creatinine clearances were done according to the method of Holten and Rehberg (22). Urea clearances were done by the method of Möller, McIntosh, and Van Slyke (21). The urea clearance was calculated by the method of Chesley (16) when the rate of urine excretion was less than $0.35 \mathrm{cc}$. per minute. In practically all cases the urine collection was made by catheter. Values for blood and urine urea are expressed as urea nitrogen.

\section{SUMMARY OF CLINICAL DATA}

Table $I$ is a summary of the 17 cases. The maximum blood urea nitrogen and nonprotein nitrogen, day of admission after onset of hemorrhage, the severity of hemorrhage as estimated by the red blood cell count, blood pressure, and renal

TABLE I

Summary of 17 cases of upper gastro-intestinal hemorrhage

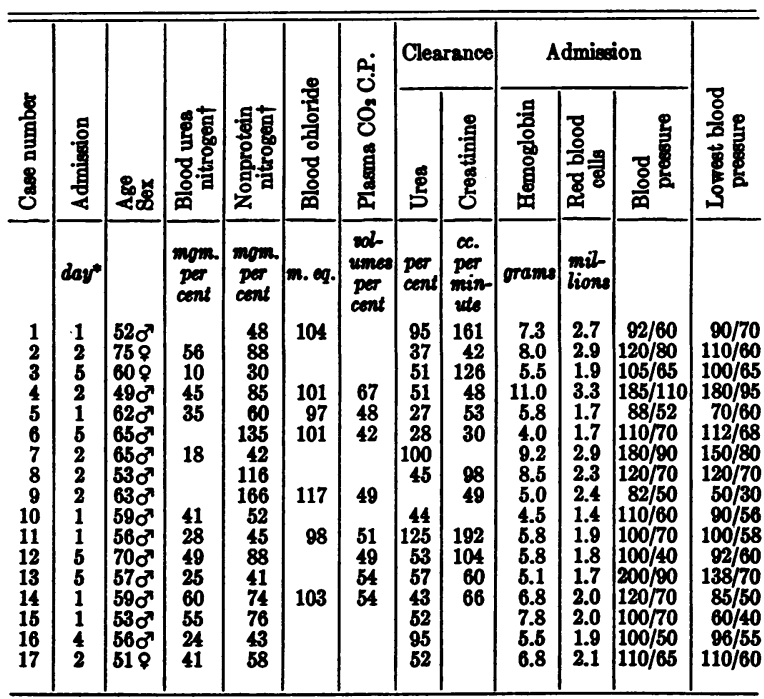

* Day of admission after onset of hemorrhage. $\uparrow$ Maximum values during hospital course. 


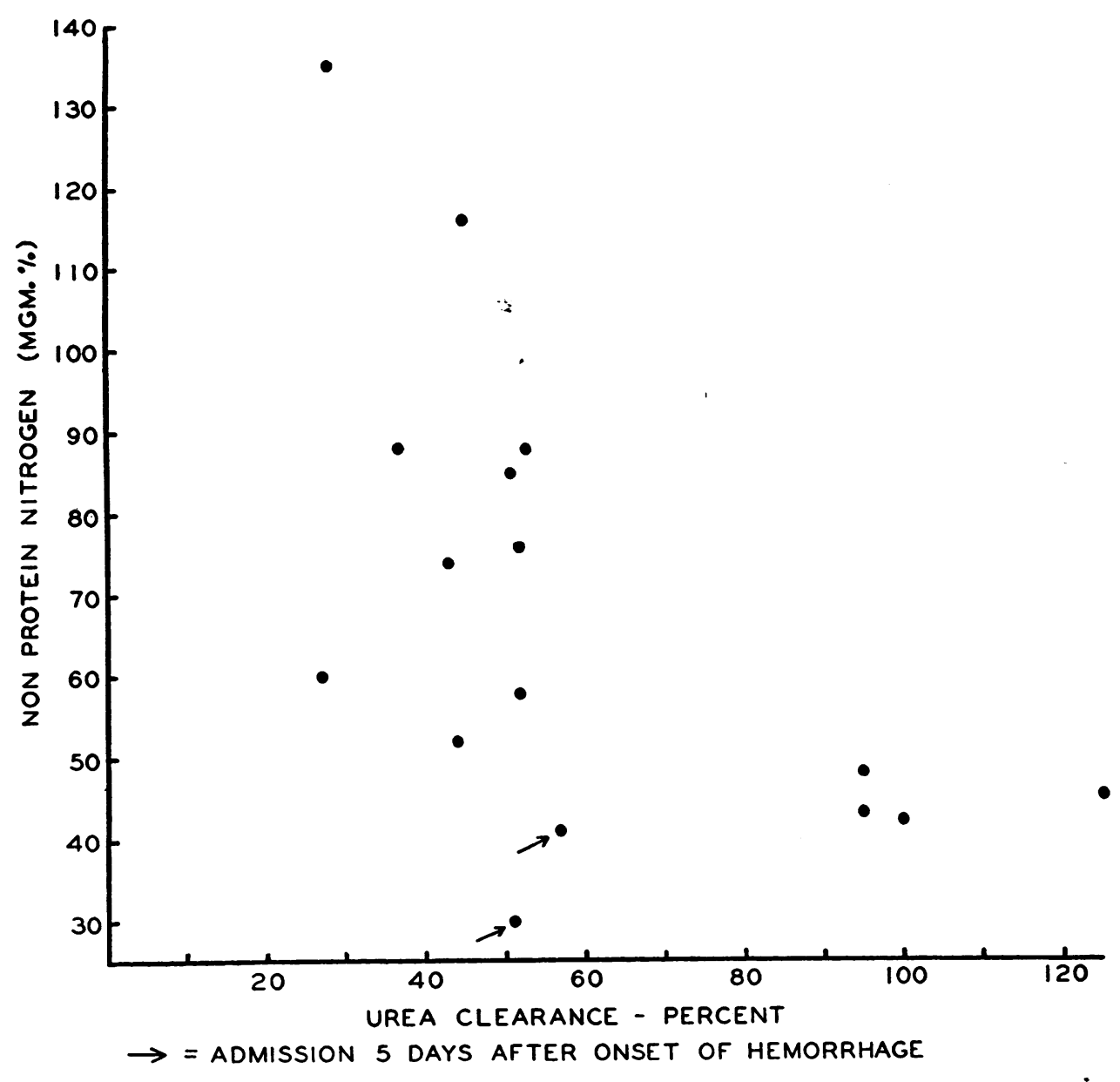

Fig. 1. Comparison of Blood Nonprotein Nitrogen and Renal Function

function are listed. The azotemia which was observed in this group of patients occurred, for the most part, in the absence of shock.

Cases 1 and 11 are striking in that they entered the hospital on the day of onset, had severe hemorrhages, but showed no significant elevation of the blood nitrogen during the period of observation. Case 7 was similar, although his blood was examined the day after onset of hemorrhage. These 3 are the only cases in the series which showed consistently normal renal function. All the other cases entering the hospital prior to the third day after the onset of severe hemorrhage had a significant rise in the blood nonprotein nitrogen. Also, they had a marked reduction in renal function. Figure 1 is a comparison of the blood nonprotein nitrogen and the renal function. The correlation between the two is even more striking when the course of this type of azotemia is considered.

The course of the blood nonprotein nitrogen in 6 representative cases is presented in Table II. In Cases 2 and 4 the clinical evidence was that of a single massive hemorrhage. Although these 2 patients developed a significant azotemia, the nonprotein nitrogen levels were again within normal limits of physiological variation on the fourth and fifth days after the hemorrhage had occurred. The course was more prolonged in Cases 14 and 15 ; in these patients there were repeated hemorrhages after admission to the hospital. Obviously, when there has been a single massive hemorrhage, a rise in the blood nonprotein nitrogen may be missed if the blood is not examined within the first 3 days after onset.

The hemorrhage was severe in all cases, but 
TABLE II

Course of blood nonprotein nitrogen after gastric hemorrhage

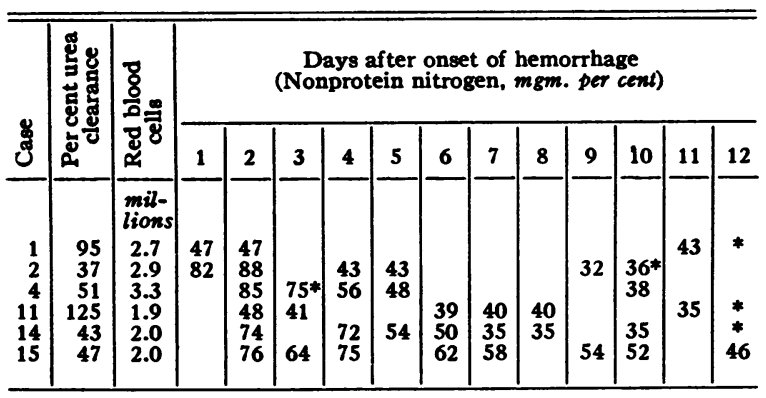

* = First guaiac negative stool.

there was considerable variation in the maximum blood urea nitrogen levels. The lack of direct correlation between the severity of hemorrhage and the maximum blood urea nitrogen can be seen in Table $\mathrm{I}$.

\section{Metabolism after hemorrhage}

Information concerning the protein metabolism incident to upper gastro-intestinal hemorrhage was obtained through the following experiment: $\mathrm{Ci}-$ trated human blood (1200 to $1500 \mathrm{cc}$.) was given to 4 patients by stomach tube within a period of 6 to 8 hours. These patients were given a constant nitrogen intake for 5 days preceding the administration of the blood. Their renal function was measured during the preceding 72 hours. The blood urea nitrogen rose in all cases as is usual after the ingestion of protein $(11,15,20)$.
However, the rise was moderate and transient in the cases with normal renal function.

In Case 14, in whom the urea clearance was 50 per cent, the blood urea nitrogen reached 54 mgm. per cent and remained above $24 \mathrm{mgm}$. per cent for 72 hours. At the end of 24 hours the nitrogen ( 37.5 grams) derived from the $1250 \mathrm{cc}$. of blood ingested by this patient could be accounted for as follows: Nitrogen retained in the body water, estimated from a rise of $34 \mathrm{mgm}$. per cent in the blood nonprotein nitrogen, 15.5 grams; nitrogen excreted in the urine, 13.8 grams; extra nitrogen finally excreted in the feces, 8.7 grams; total nitrogen accounted for, 38 grams. Figure 2 gives a graphic illustration of this distribution. Nitrogen balance studies in the other 3 cases likewise indicated that the ingested blood was the source of protein responsible for the increase in urea production. Only 20 to 30 per cent of the nitrogen given as blood could be recovered in the stools when these were collected until the guaiac reaction became negative. The control stool nitrogen before the ingestion of blood and after the feces became free of blood was within normal limits and essentially the same. On the other hand, excess nitrogen amounting to 50 to 54 per cent of the nitrogen given as blood appeared in the urine. Results similar to those just noted were obtained in Case 14 when an equivalent amount of beef serum protein was ingested (see Figure 4). The effect of another type of protein was tested in another patient by
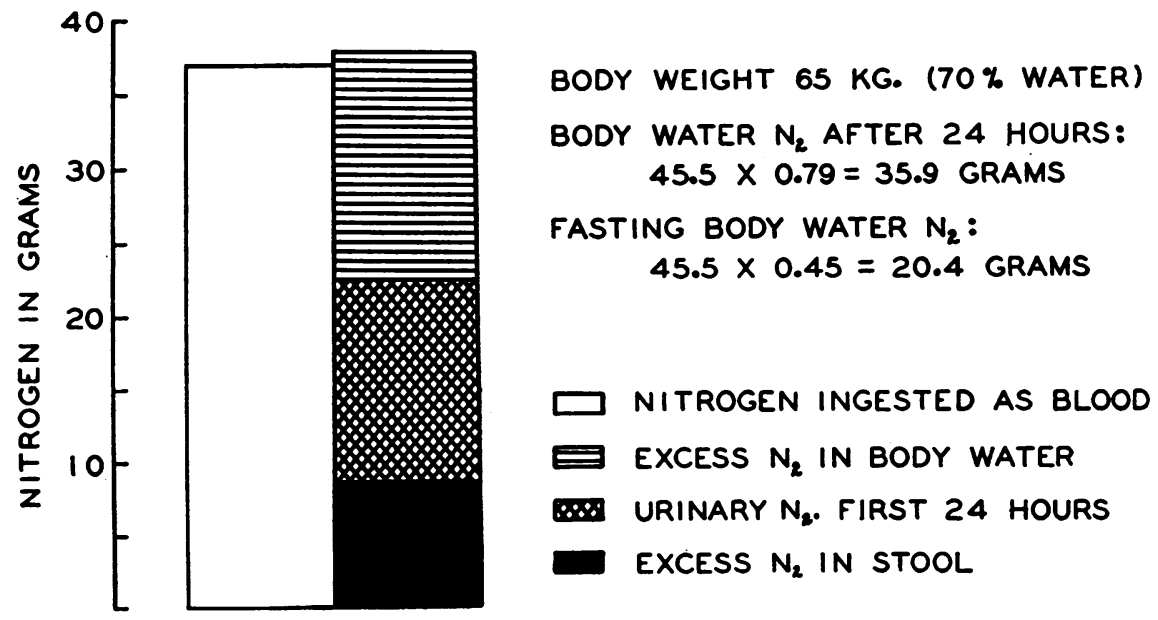

Fig. 2. Distribution of Nitrogen 24 Hours After Ingestion of 1250 cc. of Blood 


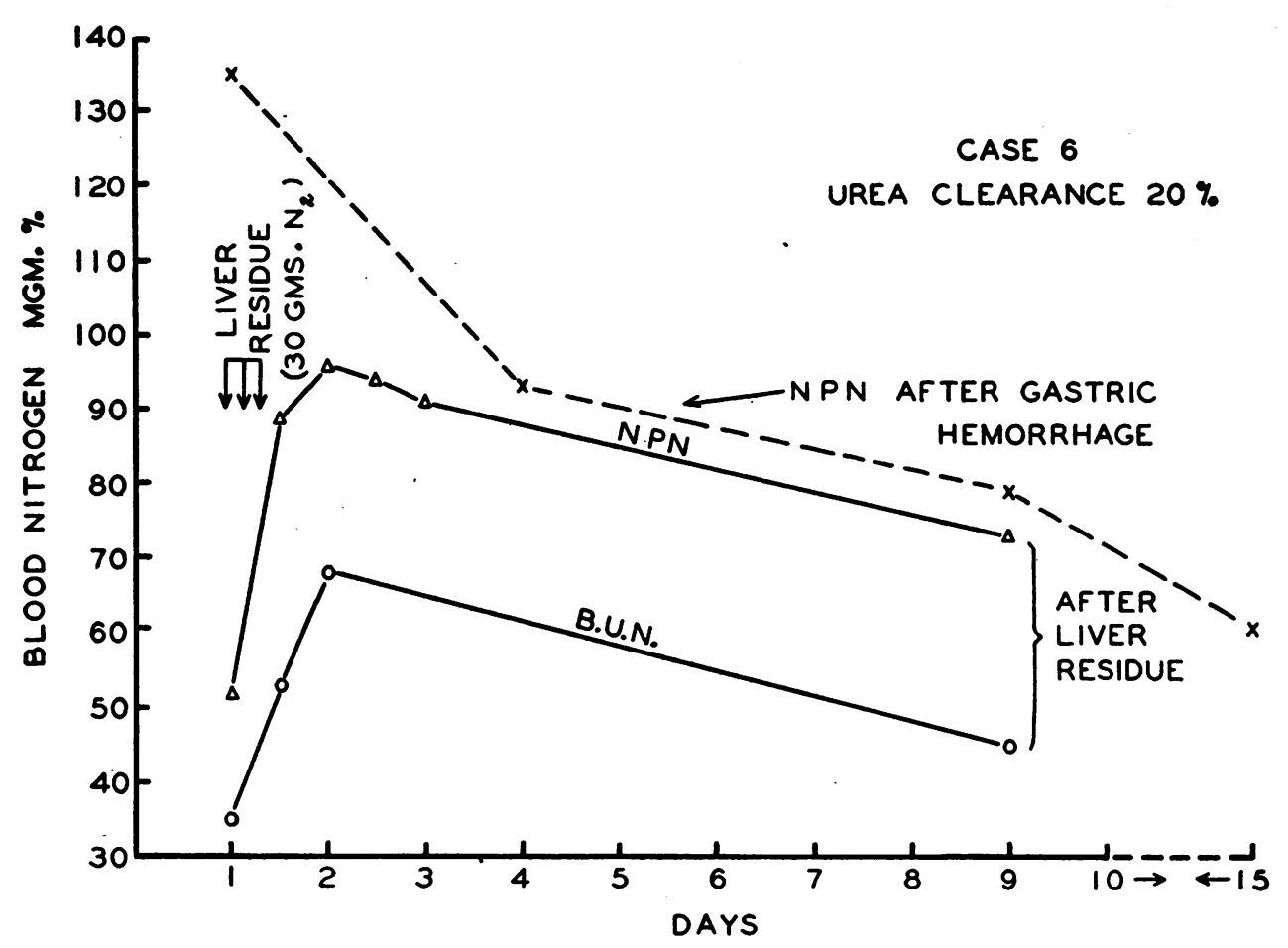

Fig. 3. Course of Blood Nonprotein Nitrogen After Gastric Hemorrhage and After InGESTION OF LIVER RESIDUE
N.P.N. $=$ Nonprotein nitrogen
B.U.N. = Blood urea nitrogen

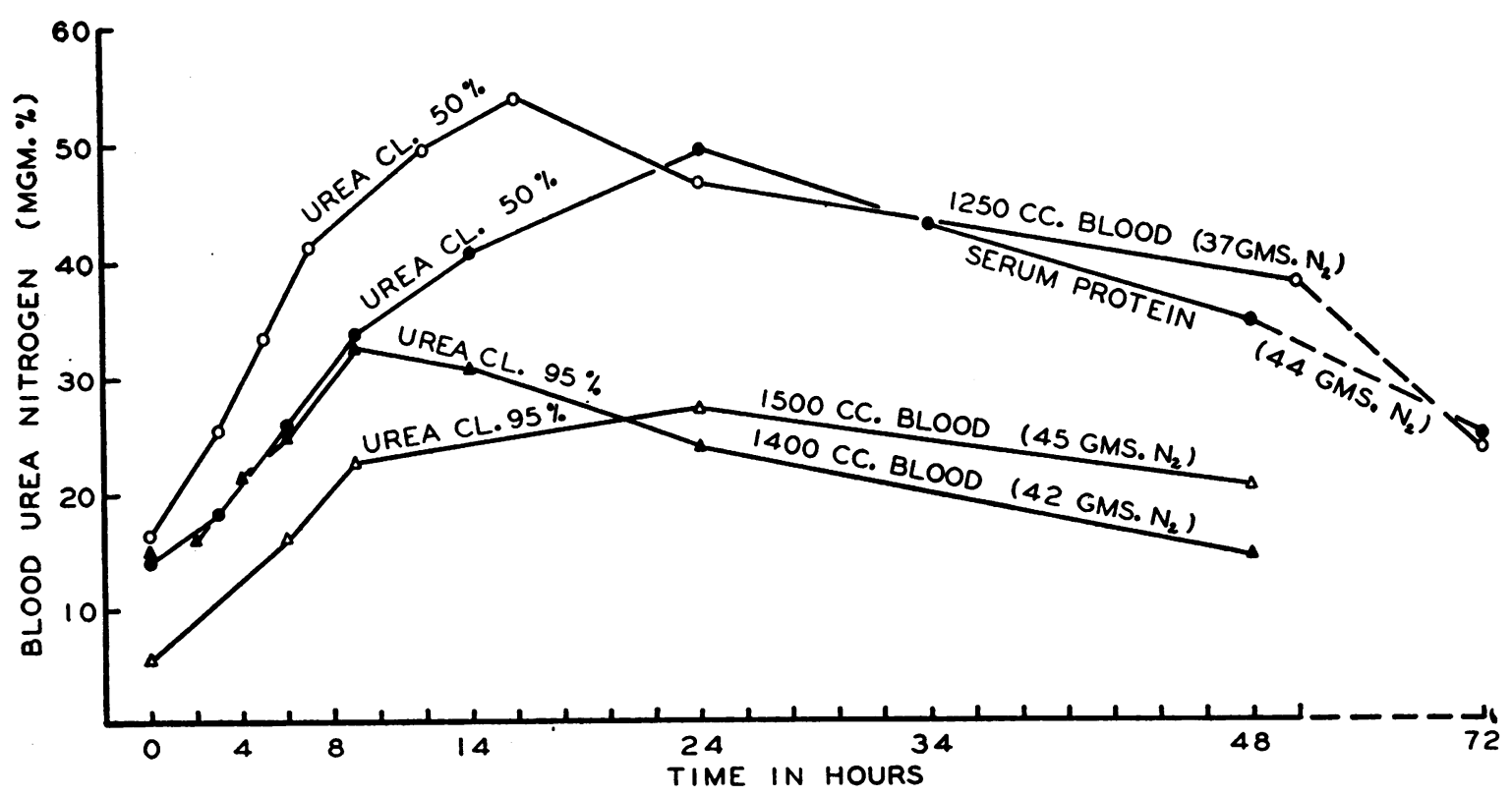

Fig. 4. Elevation of Blood Urea Nitrogen After Ingestion of Citrated Human Blood and Beef Serum Protein 
feeding liver residue. The behavior of the blood nonprotein nitrogen is shown in Figure 3, where it may be compared with the azotemia produced in this same individual by a massive spontaneous gastric hemorrhage.

An indication of the magnitude of the protein metabolism which takes place after gastric hemorrhage may be obtained from a study made on Case 14 shortly after admission to the hospital. During a period of 2 hours and 40 minutes, the urinary urea nitrogen output was 2.85 grams, at a time when the blood urea nitrogen was $50 \mathrm{mgm}$. per cent. If these conditions were continued for 12 hours, at least 214 grams of protein would be required for the production of the urea involved.

\section{Renal function after hemorrhage}

The data on renal function are shown in Table III. In most of the patients with reduced renal function, repeated measurement continued to show that impairment as long as 4 weeks after admission. The high incidence of impaired renal function was unexpected in that only 2 of these patients had positive histories and urinary findings of glomerulonephritis. It does not seem likely that the anemia was directly responsible for the impairment in view of the fact that those patients with normal renal function had equally severe anemia. In the cases in which the impairment of renal function was temporary, the fall in blood pressure was probably responsible.

As a whole, the patients with marked elevation in the nonprotein nitrogen recovered as rapidly as those with no significant elevation. The patients in whom the reduced renal function was incident to repeated fall in blood pressure had a more stormy course during the initial phase of their illness. No evidence was found to indicate that this type of azotemia represents a serious intoxication. However, the patients who ingested blood by stomach tube developed one or more loose stools consisting of partially digested blood within 7 hours after the feeding was started. Two of the patients became nauseated and vomited. A slight rise in temperature was noted in these latter cases.

The degree of azotemia was not a reliable index to the severity of the hemorrhage, but a progressive daily decline showed good correlation with
TABLE III

Course of renal function in gastro-intestinal hemorrhage *

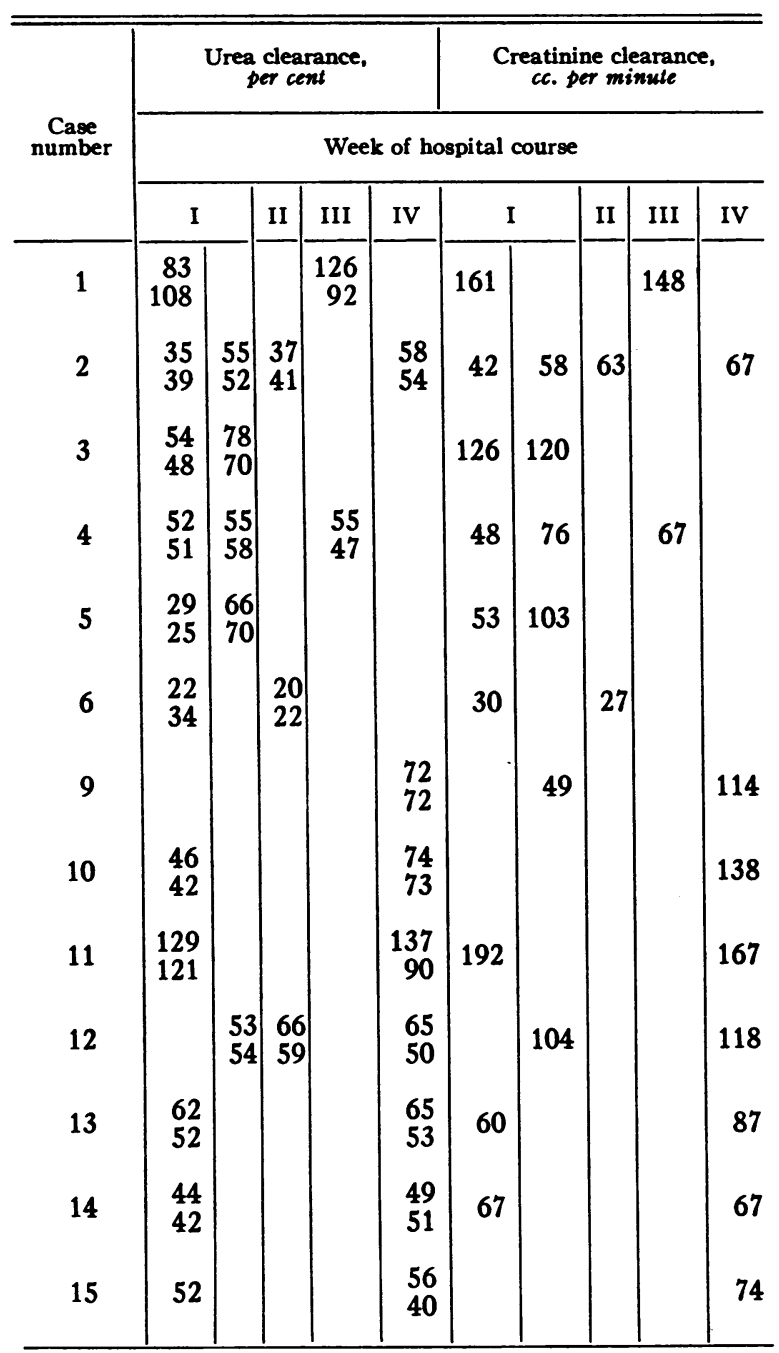

* Urea clearances done in duplicate. Creatinine and urea clearances done simultaneously. Normal creatinine clearance 170 cc. per minute (26).

the clinical evidence of cessation of hemorrhage. One patient in the group died (Case 10). He had repeated hemorrhages during the month prior to admission to the hospital. A final massive hemorrhage was responsible for his death.

\section{DISCUSSION}

In view of the fact that the elimination of urea from the body is effected primarily by the kidney, it seems reasonable that attention should be focused on renal function in the type of azotemia under consideration. The blood urea nitrogen 
ranges from 5 to $23 \mathrm{mgm}$. per cent in the normal subject on a diet containing one gram of protein per kilo. body weight (15). From a physiological point of view the level of blood urea nitrogen is a function of urea production by the liver and urea excretion by the kidneys. It is conceivable that the production of urea may increase with such rapidity that it will exceed the excretory capacity of the kidneys and result in a rise in the blood urea nitrogen.

Evidence that the rate of urea formation is enormously increased when large amounts of blood enter the upper gastro-intestinal tract is to be found in our nitrogen balance experiments described above. In Case 14 the urinary urea nitrogen during the first 24 hours was 11.4 grams. The excess urea nitrogen in the body fluids at the end of 24 hours was 15.5 grams. This makes a total of $\mathbf{5 7}$ grams of urea formed during the 24 hours after the ingestion of blood. The urea production during this period is five times that of the control period in which the daily urine urea was 10 grams ( 4.8 grams urea nitrogen). If the renal function is reduced, either by a fall in blood pressure or by organic disease of the kidney, the elevation of blood urea nitrogen which follows the increased production of urea may be greatly accentuated.

The correlation between the elevation of blood urea nitrogen and the existing renal function in the cases presented here indicates that renal function is a most important factor in determining whether a given patient with a large gastric hemorrhage will develop a significant azotemia (see Figure 4).

Only a few reports on this subject are available in which adequate renal function studies have been recorded. The most recent paper is that of Stevens and co-authors (17), who studied kidney function in 4 cases. In each of their last 3 cases two or more of the urea clearance periods varied between 40 and 60 per cent of normal (corrected to 1.73 square meters surface area). Their first case was admitted to the hospital in shock (25). After a few hours the blood pressure rose from $80 / 60$ to $122 / 60$ and remained above that level during the remainder of the hospital stay. The urea clearances were done on the second hospital day, at which time they were within the normal range. Black (23) reported 12 cases of hema- temesis in which renal function was studied. His data do not include the day after onset of hemorrhage on which the blood urea determination and urea clearances were made. That information is of much importance because of the transient nature of this type of azotemia. Even though his data are inadequate for analysis from our point of view, it is of considerable interest to note that the blood urea nitrogen did not exceed $20 \mathrm{mgm}$. per cent in any of his patients who had consistently normal renal function. Borst (6) reported 3 cases with azotemia in which the urea clearance fell to 15 per cent or less, associated with shock. In another paper this author reports 5 cases with azotemia (24). Three of these cases showed reduced renal function $(19,47$, and 58 per cent of normal). The other 2 cases had normal renal function when determined several days after admission. Of these 2, Case 5 was admitted in shock with a blood pressure of $60 / 30$. The urea clearance done on the third hospital day was normal. No statement concerning shock was made in his discussion of the other patient (Case 3 ). However, the patient received $700 \mathrm{cc}$. of blood by transfusion and considerable parenteral fluids during the first 48 hours. The urea clearance was done at some period during the second 24 hours. Alsted (12) reported 5 cases in which the renal function was studied. Four of these had normal renal function and the maximum blood urea nitrogen ranged from $23 \mathrm{mgm}$. per cent to $27 \mathrm{mgm}$. per cent. The other patient showed a fall in the urea clearance to 15 per cent with a rise in the blood urea nitrogen to $100 \mathrm{mgm}$. per cent. Clausen (7) reported 3 cases, all of whom showed a reduction in the urea clearance $(38,54$, and 68 per cent). The data in Christiansen's cases (8) are too inadequate to allow definite conclusions.

It is seen from this brief review of the literature that a reduction in the urea clearance (10 to 60 per cent of normal) is a common finding in patients with a significant rise in the blood urea nitrogen following upper gastro-intestinal hemorrhage. Stevens and associates (17), in discussing the renal factor in this type of azotemia, point out that for the most part the urea clearances were not reduced below 20 per cent of normal. They cite Peters and Van Slyke to the effect that the urea clearance must be reduced to 20 per cent of normal before all cases of impaired renal function 
show an elevated blood urea nitrogen. However, Peters and Van Slyke (18) also state that the blood urea nitrogen can be interpreted correctly only when considered in connection with the rate of urea formation. Indeed they point out that, if the protein intake is sufficiently reduced, many patients with extensive renal damage may continue to have a normal blood urea nitrogen. In the fasting state the urea clearance must be reduced at least to 20 per cent before the rate of urea formation exceeds the rate of urea excretion. When the rate of urea production is significantly increased, the rate of urea excretion will be exceeded with less severe reduction in the urea clearance.

Christiansen (8) suggested that a lack of blood chloride may be responsible for the azotemia of hemorrhage. That hypochloremia may result in azotemia seems established by the careful experiments in man by McCance (14). The rise in blood urea nitrogen which he observed was associated with a progressive decrease in renal function, although there was no change in blood pressure. None of the cases in our series in which the blood chloride was determined, showed hypochloremia (see Table I). No change was found in the blood chloride of Case 14 after the ingestion of blood. The plasma carbon dioxide combining power was not abnormal in this group of cases.

\section{CONCLUSION}

1. A marked rise in the nonprotein and urea nitrogen of the blood was observed in cases of severe upper gastro-intestinal hemorrhage only when there was a temporary or permanent reduction in renal function.

2. The duration of the azotemia was 3 to 5 days after a single hemorrhage, but was more prolonged when there were repeated hemorrhages.

3. No changes were observed in the serum chloride or in the plasma carbon dioxide combining power.

4. Whole blood in the upper gastro-intestinal tract is digested and absorbed, and results in the formation of urea.

5. The pathogenesis of the azotemia depends on a rate of urea formation which is in excess of the rate at which urea can be excreted by the kidneys.

6. No definite correlation between the degree of azotemia and the prognosis for recovery was found.

7. The absence of azotemia in some patients with massive hemorrhage into the upper gastrointestinal tract may be explained by the fact that these patients have normal renal function. In them the rate at which urea is excreted quickly equals the rate of increased urea production.

Grateful appreciation is expressed to Dr. Samuel H. Bassett for many valuable criticisms and suggestions during the course of this work.

\section{BIBLIOGRAPHY}

1. Sanguinetti, L. V., Azohemias en el curso de las Hemorragias retenidas a nivel del tubo digestivo. Arch. Argent. de enferm. d. ap. digest, y. de la nutricion, 1934, 9, 264.

2. Meyler, L., Post haemorrhagic uraemia. Acta Med. Scandinav., 1935, 87, 313.

3. Bookless, A. S., Uraemia after haemorrhage. Guy's Hosp. Rep., 1938, 88, 22.

4. Christiansen, T., Hyperazotaemia in intraintestinal haemorrhage. Acta. Med. Scandinav., 1936, Supp. 78, 894.

5. Ingegno, A. P., The elevated blood urea of acute gastro-intestinal hemorrhage and its significance. Am. J. Med. Sc., 1935, 190, 770.

6. Borst, J. G. G., The cause of hyperchloremia and hyperazotemia in patients with recurrent massive hemorrhage from peptic ulcer. Acta. Med. Scandinav., 1938, 97, 68.

7. Clausen, J., Hyperazotemia in cases of acute ventricle hemorrhage. Acta. Med. Scandinav., 1936, Supp. 78, 908.

8. Christiansen, T., Uraemia as cause of death in massive haemorrhage from peptic ulcer. Acta. Med. Scandinav., 1935, 85, 333.

9. Witts, L. J., Hematemesis and melena. Brit. M. J., $1937,1,847$.

10. Crohn, B. B., and Lerner, H. H., Gross hemorrhage as a complication of peptic ulcer. Am. J. Digest. Dis., 1939, 6, 15.

11. Schiff, L., and others, Observations on the oral administration of citrated blood in Man. Am. J. Digest. Dis., 1939, 6, 597.

12. Alsted, G., Further studies on azotemia following hemorrhage in the digestive tract. Am. J. Med. Sc., 1936, 192, 199.

13. Wood, I. J., Treatment of haemorrhage. Brit. M. J., 1936, 2, 115.

14. McCance, R. A., and Widdowson, E. M., The secretion of urine in man during experimental salt deficiency. J. Physiol., 1937, 91, 222.

15. MacKay, E. M., and MacKay, L. L., The concentration of urea in the blood of normal individuals. J. Clin. Invest., 1927, 4, 295. 
16. Chesley, L. C., The validity of the calculation of the standard urea clearances from low urine volumes. J. Clin. Invest., 1937, 16, 653.

17. Stevens, R. J., and others, Renal function and the azotemia following hematemesis. J. Clin. Invest., 1940, 19, 233.

18. Peters, J. P., and Van Slyke, D. D., Quantitative Clinical Chemistry, Vol. I, Williams and Wilkins, Baltimore, 1931, p. 358.

19. Peters, J. P., and Van Slyke, D. D., Quantitative Clinical Chemistry, Vol. II, Williams and Wilkins, Baltimore, 1932, p. 296.

20. Witts, L., Observations on the metabolism of amino acids in health and disease. Quart. J. Med., 1929, 22, 477.

21. Möller, E., McIntosh, J. F., and Van Slyke, D. D.,
Studies of urea excretion. II. Relationship between urine volume and the rate of urea excretion by normal adults. J. Clin. Invest., 1928, 6, 427.

22. Holten, C., and Rehberg, P. B., Studies on the pathological function of the kidneys in renal disease. Acta. Med. Scandinav., 1931, 74, 479.

23. Black, D. A. K., Urea clearance in haematemesis. Lancet, 1939, 1, 323.

24. Borst, J. G. G., Uber Erhöhung des Kochsalz- und Harnstoffgehaltes und Erniedrigung des Albumingehaltes des Blutes bei Patienten mit starken Magenblutungen. Ztschr. f. klin. Med., 1936, 130, 74.

25. Stevens, R. J., Personal communication.

26. Smith, H., The Physiology of the Kidney, Oxford University Press, New York, 1937, p. 98. 